\title{
Urate-lowering therapy for gout and asymptomatic hyperuricemia in the pediatric population: a cross-sectional study of a Japanese health insurance database
}

\author{
Masataka Honda ${ }^{1}$, Hideki Horiuchi ${ }^{*}$, Tomoko Torii ${ }^{2}$, Akihiro Nakajima ${ }^{3}$, Takeshi lijima ${ }^{4}$, Hiroshi Murano ${ }^{4}$, \\ Hisashi Yamanaka, ${ }^{5,6,7}$ and Shuichi Ito ${ }^{8}$
}

\begin{abstract}
Background: Our previous research showed that uric acid lowering therapy (ULT) for gout and hyperuricemia is being prescribed for pediatric patients even though these drugs have not been approved for use in children. However, the actual clinical situation has not been clearly elucidated. In this paper, we provide an in-depth look at the details of actual clinical practice.

Methods: This retrospective cross-sectional study accessed health insurance data for 696,277 children from April 2016 through March 2017 to identify pediatric patients with gout or asymptomatic hyperuricemia, calculate the proportion of patients prescribed ULTs, and analyze population characteristics. Adherence and mean dose for febuxostat and allopurinol, the most commonly prescribed drugs, were also analyzed.

Results: Among children with gout or asymptomatic hyperuricemia, we found that 35.1\% (97/276) were prescribed ULT. This proportion increased with age, especially among males. By comorbidity, ULT was prescribed to 47.9\% (46/96) of patients with kidney disease, 41.3\% (26/63) for cardiovascular disease, 40.0\% (6/15) for Down syndrome, and 27.1\% (32/118) for metabolic syndrome. In patients with kidney disease, febuxostat was prescribed more than twice as frequently as allopurinol (28 vs. 12). Median values for the medication possession ratio (MPR) of febuxostat and allopurinol were 70.1 and $76.7 \%$, respectively, and prescriptions were continued for a relatively long period for both drugs. Both drugs were prescribed at about half the adult dose for patients 6-11 years old and about the same as the adult dose for patients 12-18years old.
\end{abstract}

Conclusions: This study showed that the continuous management of serum uric acid is being explored using off-label use of ULT in pediatric patients with gout or asymptomatic hyperuricemia in Japan. Drug selection is based on patient characteristics such as sex, age, and comorbidities, and pediatric dosage is based on usage experience in adults. To develop appropriate pediatric ULT, clinical trials are needed on the efficacy and safety of ULT in the pediatric population.

Trial registration: UMIN000036029.

\footnotetext{
${ }^{*}$ Correspondence: h.horiuchi@teijin.co.jp

${ }^{2}$ Medical Science Department, Teijin Pharma Limited, Kasumigaseki

Common Gate West Tower, Kasumigaseki 3-2-1, Chiyoda-ku, Tokyo

100-8585, Japan

Full list of author information is available at the end of the article
}

(c) The Author(s) 2021. Open Access This article is licensed under a Creative Commons Attribution 4.0 International License, which permits use, sharing, adaptation, distribution and reproduction in any medium or format, as long as you give appropriate credit to the original author(s) and the source, provide a link to the Creative Commons licence, and indicate if changes were made. The images or other third party material in this article are included in the article's Creative Commons licence, unless indicated otherwise in a credit line to the material. If material is not included in the article's Creative Commons licence and your intended use is not permitted by statutory regulation or exceeds the permitted use, you will need to obtain permission directly from the copyright holder. To view a copy of this licence, visit http://creativecommons.org/licenses/by/4.0/. The Creative Commons Public Domain Dedication waiver (http://creativeco mmons.org/publicdomain/zero/1.0/) applies to the data made available in this article, unless otherwise stated in a credit line to the data. 
Keywords: Database, Epidemiology, Gout, Hyperuricemia, Children, Hyperuricemia drug therapy

\section{Background}

Gout and asymptomatic hyperuricemia are treated to reduce the painful symptoms of gouty arthritis and gout tophi, and also to prevent the development of goutrelated kidney disease and uric acid kidney stones. In pediatric patients with persistent hyperuricemia, dualenergy computerized tomography scans show urate crystal deposition very similar to that seen in adults with persistent hyperuricemia [1-3]. However, the causes of hyperuricemia in adult patients are more often related to lifestyle, while hyperuricemia in pediatric patients is usually due to underlying chronic disease, including cardiovascular and kidney disease, and to inborn errors of metabolism [4-15].

In a previous study, we accessed a Japanese health insurance database to study the incidence and prevalence of gout and of asymptomatic hyperuricemia in children and to investigate patient characteristics in that population [16]. To the best of our knowledge, that report was the first description of pediatric gout and asymptomatic hyperuricemia in a real-world clinical setting. Our findings showed that a certain number of pediatric patients had gout or asymptomatic hyperuricemia and that the prevalence of these conditions increased with age. In particular, many pediatric patients with gout or asymptomatic hyperuricemia also had cardiovascular disease and/or kidney disease. After puberty, we also noted an increase in the number of patients with comorbid metabolic syndrome associated with lifestyle-related diseases [16].

We also found that urate-lowering therapy (ULT) was frequently prescribed for pediatric patients with gout or asymptomatic hyperuricemia, even though those drugs have not yet been approved for pediatric indications in Japan [16]. In adult gout patients, ULTs are typically prescribed to prevent the development of gouty arthritis by reducing serum uric acid levels to $<6.0 \mathrm{mg} / \mathrm{dL}$ [17-21]. In general, pediatric studies tend to have markedly fewer patients than studies in adults, and each drug formulation and dosage must be investigated in each age group within the pediatric population. These factors, which contribute to delays in drug development, also apply to gout and hyperuricemia in pediatric patients. As a result, ULT is not yet internationally approved for gout or hyperuricemia in children, and there is almost no mention of pediatric gout or hyperuricemia in treatment guidelines in Europe and the United States [17, 18]. There are thus very few reports of ULT to treat hyperuricemia in pediatric patients with gout, and the real-world status of such treatment has not been clearly documented.

Unlike Europe and the United States, Japan considers the risk of gouty arthritis in hyperuricemic individuals, and ULT is recommended for adults with asymptomatic hyperuricemia who do not have a history of gout but do have serum uric acid $\geq 8.0 \mathrm{mg} / \mathrm{dL}$ and renal or cardiovascular comorbidities, as well as for otherwise healthy patients who have serum uric acid $\geq 9.0 \mathrm{mg} / \mathrm{dL}[19,20]$. However, almost no research has been published on how these adult treatment conditions affect therapeutic interventions in hyperuricemic children, particularly those with asymptomatic hyperuricemia.

The present cross-sectional study builds on our previous work [16], using data gathered from medical database records of patients who were covered by Japanese health insurance. Our objective was to examine the realworld clinical treatment of pediatric patients with gout or asymptomatic hyperuricemia in Japan. This type of information is needed to determine what kinds of treatments are appropriate for gout and asymptomatic hyperuricemia in children.

\section{Methods}

Most of the methodology of this study has been reported previously [16] and is summarized here.

\section{Study design}

This retrospective study accessed a health insurance database for data from April 2016 through March 2017. We used the data to investigate the prevalence of gout and asymptomatic hyperuricemia in the Japanese pediatric population during that period and to assess patient characteristics and treatment conditions. The study was registered in the UMIN Clinical Trials Registry (2019/2/27, UMIN000036029). The health insurance database was the JMDC Claims Database, one of the largest insurance claims databases in Japan, which contained information on approximately $2 \%$ of the Japanese population at the time of this study [22]. Age distribution of pediatric members was similar to that of the overall Japanese pediatric population for the period 2016 to 2017 . The database consists of anonymized information from multiple health insurance organizations that serve corporate-employed members and their families and that include diagnosis codes and drug prescription records. JMDC has permission to share some of that information with third parties for research. Patients are assigned identification numbers 
so their data can be traced through multiple hospitals and clinical facilities.

\section{Participants}

Patients were eligible for inclusion in this study if they were continuously registered in the JMDC Claims Database from April 2016 to March 2017, had been diagnosed with gout or asymptomatic hyperuricemia, and were 0 to 18 years of age as of April 2016. To exclude cases of chemotherapy-induced hyperuricemia, patients with malignant tumors were removed from consideration. "Target population" as used in this study is defined in Supplemental Appendix 1 (Table S1).

\section{Study measures}

We identified four points based on data from April 2016 to March 2017. First was the proportion of patients who received ULT for gout or asymptomatic hyperuricemia. Second was the characteristics of those patients, focusing on the four comorbidities of kidney disease, cardiovascular disease, metabolic syndrome, and Down syndrome. Except for Down syndrome, these are common comorbidities of hyperuricemia for which ULT is recommended in adult treatment guidelines in Japan [19, 20], and Down syndrome is often associated with hyperuricemia in pediatric patients $[11,12]$. Third was the number of patients who were prescribed each ULT. The drugs that are indicated for gout and hyperuricemia and were available in Japan during the study period included the xanthine oxidase inhibitors allopurinol, febuxostat [23], and topiroxostat [24], and the uricosuric agents benzbromarone and probenecid. Fourth was ULT adherence and mean dose. For this study, we expected that ULTs would be prescribed to only a few pediatric patients, so we limited our analysis to febuxostat and allopurinol, which are the most commonly prescribed ULTs in adult patients [25].

The definitions of "comorbidity" and "ULT" are provided in Supplemental Appendix 1 (Table S1).

\section{Statistical methods}

Sample size was not calculated because this was a crosssectional study to investigate actual clinical situations. All insurance subscribers who met the eligibility criteria were included. The proportion of ULT prescriptions was then calculated, using the number of patients prescribed ULT as the numerator and the number of gout or asymptomatic hyperuricemia patients as the denominator. Data were calculated for all patients, males, and females, and for each age subgroup and each disease state subgroup (gout or asymptomatic hyperuricemia). The proportion of ULT prescriptions was calculated for each comorbidity in all patients and in each age subgroup. Patient characteristics (sex, comorbidities, and prescribed drugs) for the patients prescribed ULT were summarized overall and by age group.

We also calculated the number of patients prescribed each ULT drug for all patients and for subgroups of age, sex, and comorbidity. Double counting was allowed for those patients who were prescribed multiple drugs during the study period. We then calculated the number of days ULT was prescribed and the medication possession ratio (MPR; the ratio of the number of days ULT was prescribed to the 365 days from April 1, 2016 to March 31, 2017 during which the patient was eligible for that prescription) for febuxostat and allopurinol. Mean prescription doses were calculated for all patients and for each age group and were expressed as the mean and median based on the annual mean of prescriptions for each patient in the group.

For normally distributed data, mean and standard deviation (SD) were calculated. For non-normally distributed data, median and interquartile range (IQR) were calculated. Categorical variables were summarized by number and proportion of patients. All analyses and data processing were performed using SAS version 9.4.

\section{Results \\ Study population}

As previously reported [16], the study population totaled 696,277 children aged 0 to 18 years (as of April 1, 2016), based on the number of pediatric insurance subscribers who were registered in the JMDC Claim Database without interruption from April 2016 to March 2017. For this study, 276 patients identified as having gout or asymptomatic hyperuricemia were included in analysis (Fig. 1).

\section{Proportion of patients diagnosed with gout or asymptomatic hyperuricemia who received ULT}

Overall, ULT was prescribed for $35.1 \%$ (97/276) and that number trended higher with age [16]. ULT was prescribed for $37.5 \%(18 / 48)$ with gout and $34.6 \%$ (79/228) with asymptomatic hyperuricemia. Details are shown by sex and by age in Table 1 . Only one male and no females received ULT in the group $0-5$ years of age, but the proportion of ULT prescriptions increased with age, particularly in males.

\section{Proportion of ULT treatment, classified by comorbidity, in patients diagnosed with gout or asymptomatic hyperuricemia}

Among the 276 patients diagnosed with gout or asymptomatic hyperuricemia, 96 (34.8\%) had kidney disease, $63(22.8 \%)$ had cardiovascular disease, 118 (42.8\%) had metabolic syndrome, and 15 (5.4\%) had Down syndrome [16]. 


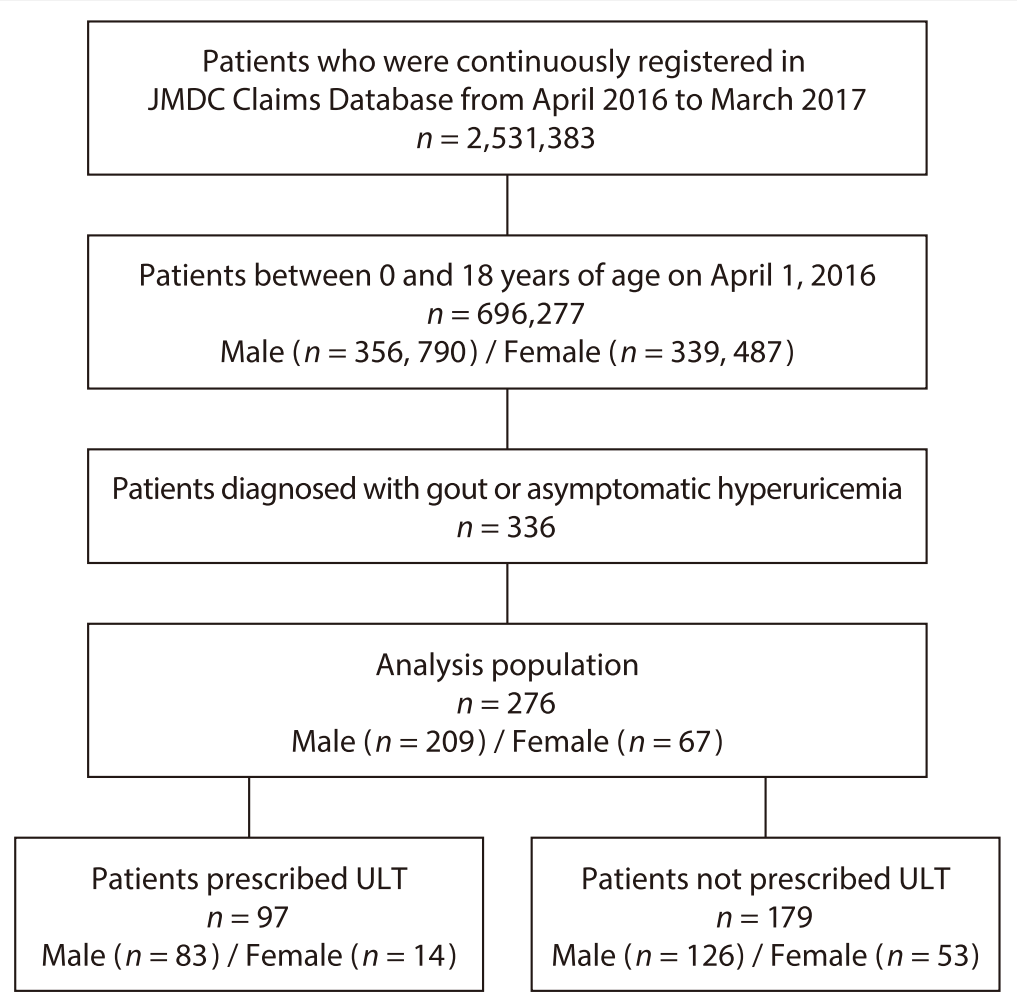

Fig. 1 Disposition of patients in the analysis set. ULT: urate-lowering therapy

The proportion of ULT prescriptions in relation to each comorbidity is shown in Fig. 2. ULT was prescribed for $47.9 \%$ of patients (46/96) with kidney disease, $41.3 \%$ (26/63) with cardiovascular disease, $27.1 \%(32 / 118)$ with metabolic syndrome, and $40.0 \%(6 / 15)$ with Down syndrome. The proportion of ULT prescriptions increased with patient age and in the 12-18 group, ULT was prescribed to $51.3 \%$ (39/76) of patients with kidney disease and $53.8 \%(21 / 39)$ of patients with cardiovascular disease. The largest subgroup within that age range consisted of 93 patients with metabolic syndrome, of whom 32.3\% (30/93) received ULT. This age group included 10 Down syndrome patients, of whom $60 \%(6 / 10)$ received prescriptions for ULT.

\section{Characteristics of patients treated with ULT}

Characteristics of the patients treated with ULT are shown in Table 2. The totals exceed total patient number because some patients had multiple comorbidities. ULT was prescribed to 97 children (83 males and 14 females). Males made up $85.6 \%$ of the ULT group and $70.4 \%$ of the non-ULT group. In the overall study population, the most common comorbidity was metabolic syndrome [16]. In the subpopulation of patients prescribed ULT, the most common comorbidity was kidney disease $(47.4 \%$, 46/97), followed by metabolic syndrome $(33.0 \%, 32 / 97)$.
Angiotensin-converting enzyme inhibitors (ACEIs) or angiotensin II receptor blockers (ARBs) were used by $24.7 \%(24 / 97)$ of the patients prescribed ULT and by $4.5 \%$ $(8 / 179)$ of the patients not prescribed ULT.

\section{Number and proportion of patients prescribed various ULTS}

Overall, 97 patients were prescribed ULTs. Febuxostat was prescribed to 54 patients, allopurinol 31, benzbromarone 15 , topiroxostat 6 , and probenecid 1 , with totals exceeding the total patient number because some patients received prescriptions for multiple ULTs (Table 3). In patients with kidney disease, febuxostat was prescribed more than twice as frequently as allopurinol (28 vs. 12).

\section{Number of days of prescription, medication possession ratio, and mean prescribed dose for ULTs (febuxostat and allopurinol)}

Febuxostat was prescribed for a median of 256.0 days (IQR 118.0, 343.0) and allopurinol for 280.0 days (IQR 118.0, 360.0) (Table 4). Median values for the MPR were 70.1 (IQR 32.3, 94.0) and 76.7 (IQR 32.3, 98.6), respectively. Overall, the mean prescribed dose $\pm S D$ in the study population was $15.0 \pm 10.2 \mathrm{mg}$ for febuxostat and $126.0 \pm 61.8 \mathrm{mg}$ for allopurinol. In the 6-11 year 
Table 1 Number and proportion of patients diagnosed with gout or asymptomatic hyperuricemia who received ULT

\begin{tabular}{|c|c|c|c|c|}
\hline & & Age & & \\
\hline & Total & $0-5$ years & $6-11$ years & $12-18$ years \\
\hline All & & & & \\
\hline All & & & & \\
\hline Diagnosed, $n$ & 276 & 22 & 43 & 211 \\
\hline Treated, $n$ (\%) & $97(35.1)$ & $1(4.5)$ & $10(23.3)$ & $86(40.8)$ \\
\hline Gout & & & & \\
\hline Diagnosed, $n$ & 48 & 3 & 7 & 38 \\
\hline Treated, $n$ (\%) & $18(37.5)$ & $0(0.0)$ & $1(14.3)$ & $17(44.7)$ \\
\hline Asymptomatic hy & peruricemi & & & \\
\hline Diagnosed, $n$ & 228 & 19 & 36 & 173 \\
\hline Treated, $n$ (\%) & 79 (34.6) & $1(5.3)$ & $9(25.0)$ & $69(39.9)$ \\
\hline Male & & & & \\
\hline All & & & & \\
\hline Diagnosed, $n$ & 209 & 10 & 23 & 176 \\
\hline Treated, $n$ (\%) & $83(39.7)$ & $1(10.0)$ & $6(26.1)$ & $76(43.2)$ \\
\hline Gout & & & & \\
\hline Diagnosed, $n$ & 33 & 1 & 2 & 30 \\
\hline Treated, $n(\%)$ & $16(48.5)$ & $0(0.0)$ & $0(0.0)$ & $16(53.3)$ \\
\hline Asymptomatic hy & peruricemi & & & \\
\hline Diagnosed, $n$ & 176 & 9 & 21 & 146 \\
\hline Treated, $n$ (\%) & $67(38.1)$ & $1(11.1)$ & $6(28.6)$ & $60(41.1)$ \\
\hline Female & & & & \\
\hline All & & & & \\
\hline Diagnosed, $n$ & 67 & 12 & 20 & 35 \\
\hline Treated, $n$ (\%) & $14(20.9)$ & $0(0.0)$ & $4(20.0)$ & $10(28.6)$ \\
\hline Gout & & & & \\
\hline Diagnosed, $n$ & 15 & 2 & 5 & 8 \\
\hline Treated, $n(\%)$ & $2(13.3)$ & $0(0.0)$ & $1(20.0)$ & $1(12.5)$ \\
\hline Asymptomatic hy & beruricemic & & & \\
\hline Diagnosed, $n$ & 52 & 10 & 15 & 27 \\
\hline Treated, $n$ (\%) & $12(23.1)$ & $0(0.0)$ & $3(20.0)$ & $9(33.3)$ \\
\hline
\end{tabular}

ULT urate-lowering therapy

group, 6 patients were prescribed febuxostat and the mean dose was $6.7 \pm 2.6 \mathrm{mg}$. In that group, 3 patients were prescribed allopurinol, and the mean dose was $74.3 \pm 28.3 \mathrm{mg}$. In the $12-18$ year group, the mean dose for febuxostat was about $16.0 \pm 10.3 \mathrm{mg}$ and for allopurinol, the mean was about $135.6 \pm 59.1 \mathrm{mg}$.

\section{Discussion}

In this study we investigated the real-world use of ULT for gout and asymptomatic hyperuricemia in children. Even at low prescription levels, we found that the ULT was selected after considering patient characteristics including patient's comorbidities, that dosage and administration were based on the experience of real-world usage in adults, and that continuous serum uric acid management was tried in pediatric patients with gout or hyperuricemia in much the same way as in adults.

Japan has a universal health insurance system to which all Japanese residents subscribe for comprehensive health insurance through their employer or an administrative agency. The cost of covered medical care is the same across the country, the co-pay for the patient is usually $30 \%$ of the total medical cost, and most local governments also offer free or discounted health care to children. Every citizen can be seen at any medical facility at any time, and various biochemical tests are performed during the process of diagnosis at those facilities. In these tests, which are covered by health insurance, the standard test panel usually includes uric acid. Thus, the Japanese healthcare system provides an environment in which hyperuricemia can be detected at a high rate and ULTs are easy to prescribe for those patients.

In the present study, we found that the highest proportion of ULT was prescribed to patients who had kidney or cardiovascular disease. In these patients with hyperuricemia and cardiovascular disease, we found a notable age-related increase in ULT prescriptions. In the kidney disease subgroup, the proportion of ULT use was particularly high in patients aged 6-11 and 12-18. Because the kidneys excrete uric acid, serum uric acid elevation is generally expected in patients with kidney disease, whether children or adults, and some papers have been published on the relationship between kidney disease and serum uric acid level [14, 26, 27]. Our study confirmed that pediatric patients with hyperuricemia and kidney disease were prescribed ULT, and our results were consistent with previous reports. ACEI/ARBs were used by $24.7 \%$ of the patients prescribed ULT, in comparison to $4.5 \%$ of patients not prescribed ULT. ACEI/ARBs are often prescribed for kidney or cardiovascular disease $[28,29]$, and these conditions may cause serum uric acid levels high enough to require treatment. However, it remains unclear whether $\mathrm{ACEI} / \mathrm{ARBs}$ elevate serum uric acid levels.

The subgroup with underlying metabolic syndrome contained the highest number of diagnosed patients, but the proportion receiving ULT was lower than for other comorbidities. The lower level of ULT in those patients may have been because this syndrome is treated primarily by lifestyle changes, and ULT is generally prescribed only if lifestyle changes are insufficient to manage the patient's condition.

In the Down syndrome group, $40.0 \%(6 / 15)$ received ULT. All 6 were $12-18$ years of age, and 5 had multiple comorbidities of kidney disease, cardiovascular disease, or metabolic syndrome. Particular caution is required from puberty, at which time Down syndrome 


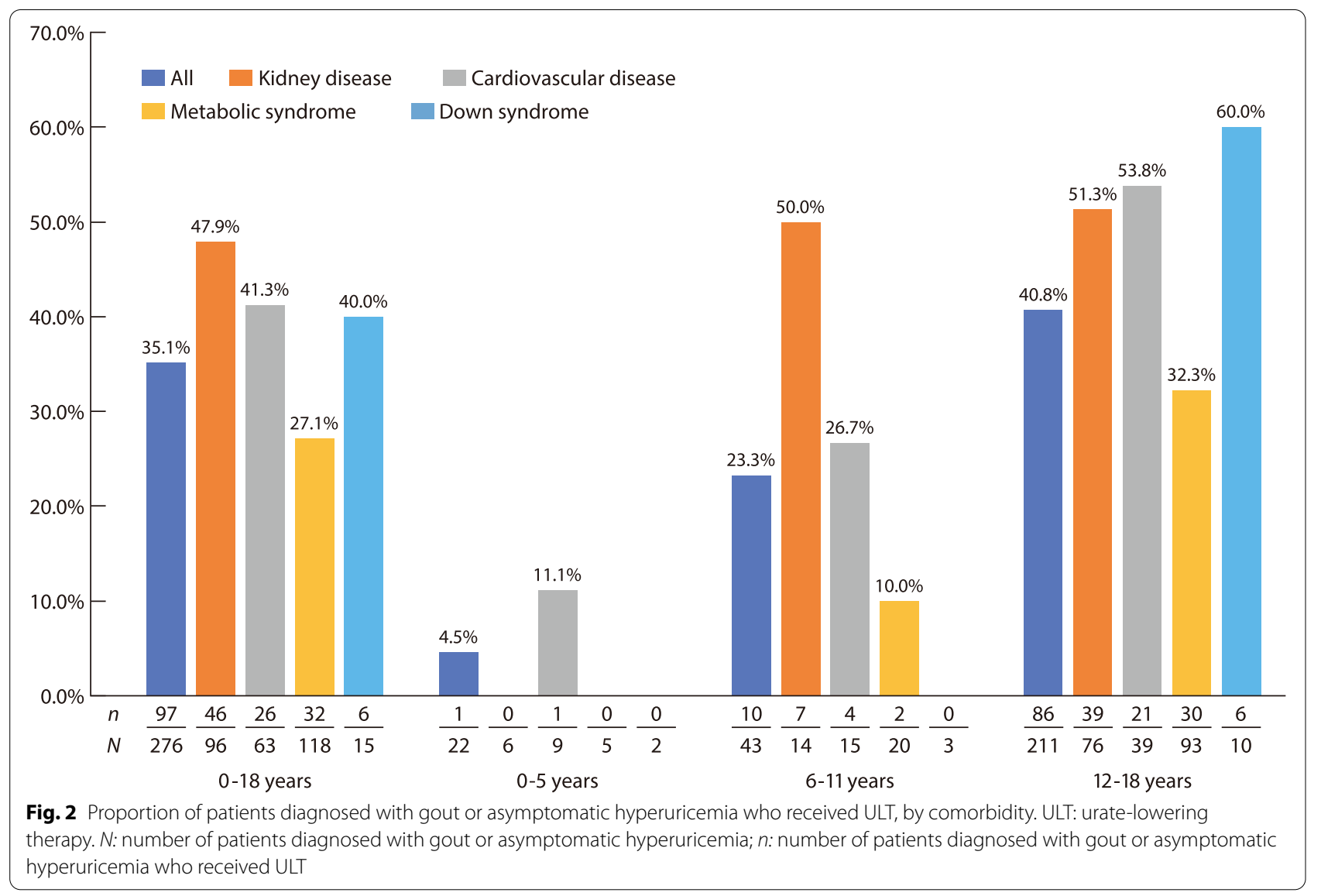

patients begin to experience increasingly high risk of hyperuricemia [12], in part because the comorbidities of lifestyle-related diseases and obesity predispose to uric acid elevation. There have been some cases in which juvenile gouty arthritis occurred in patients with Down Syndrome [11], and that background may also be related to these comorbidities.

Our study showed that febuxostat and allopurinol were the most commonly prescribed ULTs in pediatric patients. In children, MPRs for these drugs were similar to the proportion reported in adults [25]. These findings indicated that ULT was being prescribed for continuous serum uric acid management in pediatric patients in much the same way as in adults. Analysis of mean prescribed doses of febuxostat and allopurinol in pediatric patients showed that approximately half the mean prescribed dose for adults was used in patients aged 6-11 and the same amount in patients aged 12-18 [25]. This may be because the dosage for children was based on that for adults, since dosage and administration have not been established for pediatric use. The number of patients on febuxostat was highest in the kidney comorbidities subgroup, possibly because allopurinol is eliminated by the kidneys [30], while febuxostat has both hepatic and renal elimination routes [31].

In pediatric patients, chronic hyperuricemia is often associated with underlying conditions, such as cardiovascular or renal diseases, inborn errors of purine metabolism, genetic disorders, or kidney transplantation [4-15]. In contrast, hyperuricemia in adult patients is often associated with sexual differences or lifestylerelated diseases. Serum uric acid levels are known to increase with age in male children because of the effects of increased testosterone levels [4], and our previous study showed both age-based and sex-based differences in the prevalence of hyperuricemia [16]. We also found a relationship between age and metabolic syndrome [16], suggesting that adolescent hyperuricemia may be associated with lifestyle-related diseases [32, 33]. Based on the findings above, we hypothesized that the prevalence of hyperuricemia and gout increase because of overlapping factors or effects of changes in age or lifestyle during the transition from childhood to adulthood.

Particularly in patients with underlying conditions as described above, such as inborn errors of metabolism, congenital heart disease, and congenital kidney disease, 
Table 2 Characteristics of patients diagnosed with gout or asymptomatic hyperuricemia

\begin{tabular}{|c|c|c|c|c|c|c|}
\hline & \multicolumn{4}{|c|}{ Patients with ULT treatment } & \multirow{3}{*}{$\begin{array}{l}\text { Patients with no } \\
\text { ULT treatment } \\
\text { Total }(n=179)\end{array}$} & \multirow{3}{*}{$\begin{array}{l}\text { All } \\
\text { Total }(n=276)\end{array}$} \\
\hline & \multirow[b]{2}{*}{ Total $(n=97)$} & \multicolumn{3}{|l|}{ Age } & & \\
\hline & & $0-5$ years $(n=1)$ & $6-11$ years $(n=10)$ & $12-18$ years $(n=86)$ & & \\
\hline \multicolumn{7}{|l|}{ Sex, $n(\%)$} \\
\hline Male & $83(85.6)$ & $1(100.0)$ & $6(60.0)$ & $76(88.4)$ & $126(70.4)$ & $209(75.7)$ \\
\hline Female & $14(14.4)$ & $0(0.0)$ & $4(40.0)$ & $10(11.6)$ & $53(29.6)$ & $67(24.3)$ \\
\hline \multicolumn{7}{|l|}{ Comorbidity, n (\%) } \\
\hline Kidney disease & $46(47.4)$ & $0(0.0)$ & $7(70.0)$ & $39(45.3)$ & $50(27.9)$ & $96(34.8)$ \\
\hline Cardiovascular disease & $26(26.8)$ & $1(100.0)$ & $4(40.0)$ & $21(24.4)$ & $37(20.7)$ & $63(22.8)$ \\
\hline Metabolic syndrome & $32(33.0)$ & $0(0.0)$ & $2(20.0)$ & $30(34.9)$ & $86(48.0)$ & $118(42.8)$ \\
\hline Down syndrome & $6(6.2)$ & $0(0.0)$ & $0(0.0)$ & $6(7.0)$ & $9(5.0)$ & $15(5.4)$ \\
\hline \multicolumn{7}{|l|}{ Treatment and drug use, $n$ (\%) } \\
\hline Dialysis & $2(2.1)$ & $0(0.0)$ & $0(0.0)$ & $2(2.3)$ & $0(0.0)$ & $2(0.7)$ \\
\hline Cardiovascular disease drug & $5(5.2)$ & $0(0.0)$ & $4(40.0)$ & $1(1.2)$ & $4(2.2)$ & $9(3.3)$ \\
\hline Diuretic drug & $8(8.2)$ & $1(100.0)$ & $3(30.0)$ & $4(4.7)$ & $5(2.8)$ & $13(4.7)$ \\
\hline$\beta$ blocker & $5(5.2)$ & $0(0.0)$ & $2(20.0)$ & $3(3.5)$ & $2(1.1)$ & $7(2.5)$ \\
\hline Ca antagonist & $6(6.2)$ & $0(0.0)$ & $1(10.0)$ & $5(5.8)$ & $2(1.1)$ & $8(2.9)$ \\
\hline ACEl and/or ARB & $24(24.7)$ & $1(100.0)$ & $3(30.0)$ & $20(23.3)$ & $8(4.5)$ & $32(11.6)$ \\
\hline Antihyperlipidemic drug & $7(7.2)$ & $0(0.0)$ & $0(0.0)$ & $7(8.1)$ & $7(3.9)$ & $14(5.1)$ \\
\hline Antidiabetic drug & $1(1.0)$ & $0(0.0)$ & $0(0.0)$ & $1(1.2)$ & $4(2.2)$ & $5(1.8)$ \\
\hline Immunosuppressant & $9(9.3)$ & $0(0.0)$ & $5(50.0)$ & $4(4.7)$ & $9(5.0)$ & $18(6.5)$ \\
\hline Vitamin D & $7(7.2)$ & $0(0.0)$ & $2(20.0)$ & $5(5.8)$ & $6(3.4)$ & $13(4.7)$ \\
\hline
\end{tabular}

ULT urate-lowering therapy, $A C E l$ angiotensin-converting enzyme inhibitor, $A R B$ angiotensin II receptor blocker

Table 3 Number of patients prescribed various ULTS

\begin{tabular}{|c|c|c|c|c|c|}
\hline & Febuxostat & Allopurinol & Benzbromarone & Topiroxostat & Probenecid \\
\hline \multicolumn{6}{|l|}{ Age, $n$} \\
\hline Total & 54 & 31 & 15 & 6 & 1 \\
\hline $0-5$ years & 0 & 1 & 0 & 0 & 0 \\
\hline $6-11$ years & 6 & 3 & 1 & 0 & 0 \\
\hline 12-18years & 48 & 27 & 14 & 6 & 1 \\
\hline \multicolumn{6}{|l|}{ Sex, $n$} \\
\hline Male & 48 & 27 & 11 & 6 & 1 \\
\hline Female & 6 & 4 & 4 & 0 & 0 \\
\hline \multicolumn{6}{|l|}{ Comorbidity, $n$} \\
\hline Kidney disease & 28 & 12 & 7 & 4 & 0 \\
\hline Cardiovascular disease & 15 & 10 & 2 & 0 & 1 \\
\hline Metabolic syndrome & 18 & 14 & 6 & 3 & 1 \\
\hline Down syndrome & 4 & 1 & 1 & 0 & 0 \\
\hline
\end{tabular}

ULT urate-lowering therapy

chronic hyperuricemia can develop at a young age and may result in gout before the child reaches 10 years of age. This situation places an enormous burden on patients and their families. There are several case reports of pediatric gout patients who had familial juvenile hyperuricemic nephropathy or other comorbidities and whose gout became intractable in their 20 s or 30 s, resulting in joint deformity or tophus $[8-10,34,35]$. Recent years have seen increasing concern about the incidence of gout and asymptomatic hyperuricemia in children, and the potential onset of gouty arthritis at younger ages, as a result of obesity [32,33]. Previously, we reported that the risk 
Table 4 Number of days of prescription, MPR, and mean prescribed dose of ULTs (febuxostat and allopurinol)

\begin{tabular}{|c|c|c|}
\hline & $\begin{array}{l}\text { Febuxostat } \\
(n=54)\end{array}$ & $\begin{array}{l}\text { Allopurinol } \\
(n=31)\end{array}$ \\
\hline \multicolumn{3}{|l|}{ Prescription, days/year } \\
\hline Median (Q1, Q3) & $256.0(118.0,343.0)$ & $280.0(118.0,360.0)$ \\
\hline \multicolumn{3}{|l|}{ MPR } \\
\hline Median (Q1, Q3) & $70.1(32.3,94.0)$ & $76.7(32.3,98.6)$ \\
\hline \multicolumn{3}{|l|}{ Dose, mg } \\
\hline \multicolumn{3}{|l|}{ Total (0-18years) } \\
\hline Mean (SD) & $15.0(10.2)$ & $126.0(61.8)$ \\
\hline Median (Q1, Q3) & $10.0(10.0,20.0)$ & $100.0(100.0,200.0)$ \\
\hline \multicolumn{3}{|l|}{$0-5$ years $^{a}$} \\
\hline Mean & - & 18.1 \\
\hline Median & - & 18.1 \\
\hline \multicolumn{3}{|l|}{$6-11$ years ${ }^{b}$} \\
\hline Mean (SD) & $6.7(2.6)$ & $74.7(28.3)$ \\
\hline Median (Q1, Q3) & $5.5(5.0,9.9)$ & $80.0(44.2,100.0)$ \\
\hline \multicolumn{3}{|l|}{$12-18$ years $^{c}$} \\
\hline Mean (SD) & $16.0(10.3)$ & $135.6(59.1)$ \\
\hline Median (Q1, Q3) & $10.0(10.0,20.0)$ & $100.0(100.0,200.0)$ \\
\hline
\end{tabular}

ULT urate-lowering therapy, MPR medication possession ratio, $Q$ quartile, $S D$ standard deviation

${ }^{\text {a }}$ Febuxostat $(n=0)$; Allopurinol $(n=1),{ }^{b}$ Febuxostat $(n=6)$; Allopurinol $(n=3)$,

${ }^{c}$ Febuxostat $(n=48)$; Allopurinol $(n=27)$

of gouty arthritis is similar in pediatric and adult gout patients [16] and those findings emphasize the potential importance of drug therapy for pediatric patients with gout or asymptomatic hyperuricemia in whom lifestyle modification has been insufficiently effective. In such cases, ULT might prevent the deposition of urate crystals and progression to refractory disease that could occur if hyperuricemia remains untreated into adulthood [36, 37].

Because this was a database study, we were unable to investigate serum uric acid levels at the start of therapeutic intervention and after treatment, or to collect data on safety. In the near future we hope that clinical studies will be performed in pediatric patients to determine the relationship between dosage and uric acid level, to investigate the safety and tolerability of ULTs, and to establish effective drug therapy for gout and asymptomatic hyperuricemia in this population.

This study has several limitations. First, we analyzed data based on information from insurance claims (medical fee claim forms), which were not collected for research purposes, so the validity of definitions for various diseases was not assured. Second, the overall study population was less than 300 patients, and several subgroups contained only a few patients, which limits the generalizability of our findings. Third, data used were from company employees and their family members, which excluded members of other populations, reducing our findings' generalizability. Fourth, some patients had claims reimbursed through a bundled payment plan, and only limited information may have been available on prescriptions for those patients. Fifth, this was a crosssectional study with evaluation during a single period, so it was impossible to estimate the causal relationship between exposure and outcome.

\section{Conclusions}

Our study analyzed the use of ULTs in pediatric patients with gout or hyperuricemia, based on data from a Japanese health insurance claims database. Results show that the off-label use of ULTs is being explored in these patients, with drug selection based on patient characteristics and dosage based on usage experience in adults. In pediatric patients, serum uric acid management tends to be continuous, and pediatric prescriptions for ULT tend to increase with patient age, particularly in male patients and those with kidney disease. Clinical trials are needed in the near future on the efficacy and safety of ULTs in the pediatric population to establish appropriate pediatric drug therapy.

\section{Abbreviations}

ACEl: Angiotensin-converting enzyme inhibitor; ARB: Angiotensin II receptor blocker; IQR: Interquartile range; MPR: Medication possession ratio; SD: Standard deviation; ULT: Urate-lowering therapy.

\section{Supplementary Information}

The online version contains supplementary material available at https://doi. org/10.1186/s12887-021-03051-x.

Additional file 1: Table S1 List of definitions

\section{Acknowledgments}

Support for study planning and information on data handling for the database were provided by JMDC Inc. Review of the statistical analysis plan, clinical study report, and manuscript was provided by Hirotaka Mano and Satoshi Yamamura, Pharmaceutical Development Administration Department and Pharmaceutical Development Coordination Department, Teijin Pharma Limited, respectively. Medical writing support was provided by EDIT, Inc. (Tokyo, Japan) and was funded by Teijin Pharma Limited.

\section{Authors' contributions}

All authors contributed to the conceptualization, design, and methodology of the study. $\mathrm{MH}, \mathrm{HH}, \mathrm{TT}, \mathrm{AN}, \mathrm{TI}, \mathrm{HM}$, and $\mathrm{HY}$ conducted the investigation. TT, TI, and $\mathrm{HM}$ curated the data. HM, TT, AN, TI, and SI contributed to formal analysis. $\mathrm{MH}$ and $\mathrm{HH}$ wrote the first draft of the manuscript. All authors reviewed or edited the manuscript. $\mathrm{MH}, \mathrm{HY}$, and $\mathrm{TI}$ contributed to supervision and oversight of the study. $\mathrm{HH}$ acquired funding and resources. All authors read and approved the final manuscript.

\section{Funding}

This study was supported by Teijin Pharma Limited.

\section{Availability of data and materials}

The data that support the findings of this study are available from JMDC, but restrictions apply to the availability of these data, which were used under 
license for the current study, and so are not publicly available. Data are however available from the authors upon reasonable request and with permission of JMDC.

\section{Declarations}

\section{Ethics approval and consent to participate} Not applicable.

\section{Consent for publication}

Not applicable.

\section{Competing interests}

The first draft of this paper was written by $\mathrm{MH}$ and $\mathrm{HH}$, with writing and editing support from EDIT, Inc. (Tokyo, Japan) and financial support from Teijin Pharma Limited. The sponsor (Teijin Pharma Limited) designed the study, collected and analyzed data, wrote the report, and decided to submit the manuscript for publication in cooperation with the academic authors. $\mathrm{MH}$ reports personal fees from Teijin Pharma Limited; $\mathrm{HH}, \mathrm{TT}, \mathrm{AN}, \mathrm{TI}$, and HM are employees of Teijin Pharma Limited; HY reports grants and personal fees from Teijin Pharma Limited; SI reports personal fees, non-financial support, and other relationships from Teijin Pharma Limited.

\section{Author details}

${ }^{1}$ Clinical Research Support Center, Tokyo Metropolitan Children's Medical Center, Musashidai 2-8-29, Fuchu-shi, Tokyo 183-8561, Japan. ${ }^{2}$ Medical Science Department, Teijin Pharma Limited, Kasumigaseki Common Gate West Tower, Kasumigaseki 3-2-1, Chiyoda-ku, Tokyo 100-8585, Japan. ${ }^{3}$ Pharmaceutical Development Administration Department, Teijin Pharma Limited, Kasumigaseki Common Gate West Tower, Kasumigaseki 3-2-1, Chiyoda-ku, Tokyo 100-8585, Japan. ${ }^{4}$ Pharmaceutical Development Coordination Department, Teijin Pharma Limited, Kasumigaseki Common Gate West Tower, Kasumigaseki 3-2-1, Chiyoda-ku, Tokyo 100-8585, Japan. ${ }^{5}$ Rheumatology, Sanno Medical Center, Akasaka 8-5-35, Minato-ku, Tokyo 107-0052, Japan. 'Department of Rheumatology, International University of Health and Welfare, Kozunomori 4-3, Narita-shi, Chiba 286-8686, Japan. ${ }^{7}$ Institute of Rheumatology, Tokyo Women's Medical University, Kawada-cho 8-1, Shinjuku-ku, Tokyo 162-8666, Japan. ${ }^{8}$ Department of Pediatrics, Graduate School of Medicine, Yokohama City University, Fukuura 3-9, Kanazawa-ku, Yokohama-shi, Kanagawa 236-0004, Japan.

Received: 29 June 2021 Accepted: 30 November 2021 Published online: 18 December 2021

\section{References}

1. Dalbeth N, House ME, Aati O, Tan P, Franklin C, Horne A, et al. Urate crystal deposition in asymptomatic hyperuricaemia and symptomatic gout: a dual energy CT study. Ann Rheum Dis. 2015;74(5):908-11.

2. Sun N, Zhong S, Li Y, Wu L, Di Y. Urate crystals deposition in the feet of overweight juveniles and those with symptomatic hyperuricemia: a dualenergy CT study. J Pediatr Endocrinol Metab. 2016;29(5):579-83.

3. Mallinson PI, Reagan AC, Coupal T, Munk PL, Ouellette H, Nicolaou S. The distribution of urate deposition within the extremities in gout: a review of 148 dual-energy CT cases. Skelet Radiol. 2014;43(3):277-81.

4. WilcoxWD. Abnormal serum uric acid levels in children. J Pediatr. 1996;128(6):731-41.

5. Yamanaka H. Gout and hyperuricemia in young people. Curr Opin Rheumatol. 2011;23(2):156-60

6. Hayabuchi Y, Matsuoka S, Akita H, Kuroda Y. Hyperuricaemia in cyanotic congenital heart disease. Eur J Pediatr. 1993;152(11):873-6.

7. Torres RJ, Puig JG, Ceballos-Picot I. Clinical utility gene card for: LeschNyhan syndrome - update 2013. Eur J Hum Genet. 2013;21(10). https:// doi.org/10.1038/ejhg.2012.304.

8. Henriques CC, Monteiro A, Lopéz B, Sequeira L, Panarra A, Riso N. Juvenile gout: rare and aggressive. BMJ Case Rep. 2012. https://doi.org/10.1136/ bcr.12.2011.5345.
9. Morris H, Grant K, Khanna G, White AJ. Gout in a 15-year-old boy with juvenile idiopathic arthritis: a case study. Pediatr Rheumatol Online J. 2014;12:1.

10. Medeiros MM, Silva GB Jr, Daher EF. Tophus gout and chronic kidney disease in a young female patient: report of familial juvenile hyperuricemic nephropathy in three generations of the same family. Rheumatol Int. 2012;32(11):3687-90.

11. Kamatani N, Yamanaka H, Totokawa S, Kashiwazaki S, Higurashi M. Down syndrome with coexistent gout: report of six patients and possible reasons for the scarcity of descriptions of this association. Ann Rheum Dis. 1996;55(9):649-50.

12. Niegawa T, Takitani K, Takaya R, Ishiro M, Kuroyanagi Y, Okasora K, et al. Evaluation of uric acid levels, thyroid function, and anthropometric parameters in Japanese children with Down syndrome. J Clin Biochem Nutr. 2017;61(2):146-52.

13. Edvardsson VO, Kaiser BA, Polinsky MS, Palmer JA, Quien R, Baluarte HJ. Natural history and etiology of hyperuricemia following pediatric renal transplantation. Pediatr Nephrol. 1995;9(1):57-60.

14. Assadi F. Managing new-onset gout in pediatric renal transplant recipients: when, how, to what extent? J Nephrol. 2013;26(4):624-8.

15. Truck J, Laube GF, von Vigier RO, Goetschel P. Gout in pediatric renal transplant recipients. Pediatr Nephrol. 2010;25(12):2535-8.

16. Ito S, Torii T, Nakajima A, lijima T, Murano H, Horiuchi H, et al. Prevalence of gout and asymptomatic hyperuricemia in the pediatric population: a cross-sectional study of a Japanese health insurance database. BMC Pediatr. 2020;20(1):481.

17. FitzGerald JD, Dalbeth N, Mikuls T, Brignardello-Petersen R, Guyatt G, Abeles AM, et al. 2020 American College of Rheumatology Guideline for the Management of Gout. Arthritis Care Res. 2020;72(6):744-60.

18. Richette P, Doherty M, Pascual E, Barskova V, Becce F, Castañeda-Sanabria J, et al. 2016 updated EULAR evidence-based recommendations for the management of gout. Ann Rheum Dis. 2017;76(1):29-42.

19. Hisatome I, Ichida K, Mineo I, Ohtahara A, Ogino K, Kuwabara M, et al. Japanese Society of Gout and Uric \& nucleic acids 2019 guidelines for Management of Hyperuricemia and Gout 3rd edition. Gout Uric Nucleic Acids. 2020;44(Suppl):1-40

20. Yamanaka H. The guideline revising Committee of Japanese Society of gout and nucleic acid metabolism. Essence of the revised guideline for the management of hyperuricemia and gout. Japan Med Assoc J. 2012;55(4):324-9.

21. Shoji A, Yamanaka H, Kamatani N. A retrospective study of the relationship between serum urate level and recurrent attacks of gouty arthritis: evidence for reduction of recurrent gouty arthritis with antihyperuricemic therapy. Arthritis Rheum. 2004;51(3):321-5.

22. Kimura S, Sato T, Ikeda S, Noda M, Nakayama T. Development of a database of health insurance claims: standardization of disease classifications and anonymous record linkage. J Epidemiol. 2010;20(5):413-9.

23. Kamatani N, Fujimori S, Hada T, Hosoya T, Kohri K, Nakamura T, et al. An allopurinol-controlled, randomized, double-dummy, double-blind, parallel between-group, comparative study of febuxostat (TMX-67), a non-purine-selective inhibitor of xanthine oxidase, in patients with hyperuricemia including those with gout in Japan: phase 3 clinical study. J Clin Rheumatol. 2011;17(2):13-8.

24. Hosoya T, Ogawa Y, Hashimoto H, Ohashi T, Sakamoto R. Comparison of topiroxostat and allopurinol in Japanese hyperuricemic patients with or without gout: a phase 3, multicentre, randomized, double-blind, doubledummy, active-controlled, parallel-group study. J Clin Pharm Ther. 2016:41:290-7.

25. Koto R, Nakajima A, Horiuchi H, Yamanaka H. Real-world treatment of gout and asymptomatic hyperuricemia: a cross-sectional study of Japanese health insurance claims data. Mod Rheumatol. 2021;31(1):261-9.

26. Rodenbach KE, Schneider MF, Furth SL, Moxey-Mims MM, Mitsnefes MM, Weaver DJ, et al. Hyperuricemia and progression of CKD in children and adolescents: the chronic kidney disease in children (CKiD) cohort study. Am J Kidney Dis. 2015;66(6):984-92.

27. Ghane Sharbaf F, Assadi F. Effect of allopurinol on the glomerular filtration rate of children with chronic kidney disease. Pediatr Nephrol. 2018;33(8):1405-9.

28. Nakanishi K, lijima K, Ishikura K, Hataya H, Awazu M, Sako M, et al. Efficacy and safety of lisinopril for mild childhood IgA nephropathy: a pilot study. Pediatr Nephrol. 2009;24(4):845-9. 
29. Ellis D, Vats A, Moritz ML, Reitz S, Grosso MJ, Janosky JE. Long-term antiproteinuric and renoprotective efficacy and safety of losartan in children with proteinuria. J Pediatr. 2003;143(1):89-97.

30. Hande KR, Noone RM, Stone WJ. Severe allopurinol toxicity. Description and guidelines for prevention in patients with renal insufficiency. Am J Med. 1984;76(1):47-56.

31. Hosoya T, Ohno I. A repeated oral administration study of febuxostat (TMX-67), a non-purine-selective inhibitor of xanthine oxidase, in patients with impaired renal function in Japan: pharmacokinetic and pharmacodynamic study. J Clin Rheumatol. 2011;17(4):27-34.

32. Tang L, Kubota M, Nagai A, Mamemoto K, Tokuda M. Hyperuricemia in obese children and adolescents: the relationship with metabolic syndrome. Pediatr Rep. 2010;2(1):e12.

33. Oyama C, Takahashi T, Oyamada M, Oyamada T, Ohno T, Miyashita M, et al. Serum uric acid as an obesity-related indicator in early adolescence. Tohoku J Exp Med. 2006;209(3):257-62.

34. Kato R, Kubota M, Higashiyama Y, Nagai A. A nationwide epidemiological study of gout in childhood and adolescence. Gout Nucleic Acid Metab. 2014;38(1):43-7.

35. Chen SY, Kamatani N. Clinical features of juvenile gout in Taiwan. Gout Nucleic Acid Metab. 2006;30(1):27-31.

36. Lin KC, Lin HY, Chou P. The interaction between uric acid level and other risk factors on the development of gout among asymptomatic hyperuricemic men in a prospective study. J Rheumatol. 2000;27(6):1501-5.

37. Campion EW, Glynn RJ, DeLabry LO. Asymptomatic hyperuricemia. Risks and consequences in the normative aging study. Am J Med. 1987:82(3):421-6

\section{Publisher's Note}

Springer Nature remains neutral with regard to jurisdictional claims in published maps and institutional affiliations.

- fast, convenient online submission

- thorough peer review by experienced researchers in your field

- rapid publication on acceptance

- support for research data, including large and complex data types

- gold Open Access which fosters wider collaboration and increased citations

- maximum visibility for your research: over $100 \mathrm{M}$ website views per year

At BMC, research is always in progress.

Learn more biomedcentral.com/submissions 